\title{
Software engineering of interactive educational resources for university student training in urban development courses
}

\author{
Olga Solnyshkova ${ }^{1, *}$ and Elena Dudysheva ${ }^{2}$ \\ ${ }^{1}$ Novosibirsk State University of Architecture and Civil Engineering (SIBSTRIN), Leningradskaya \\ str., 113, Novosibirsk, 630089, Russia \\ ${ }^{2}$ Shukshin Altai State Humanities Pedagogical University, 659330 Biysk, Russia
}

\begin{abstract}
The article is devoted to the issues of improving the quality of training specialists in urban development with using interactive educational resources simulated work with geodetic instruments. We considered conditions for increasing the effectiveness of the university students' initial work with the equipment during software design of interactive multimedia educational resources. One is modelling of the industrial operation with the possibility of students performing correct and erroneous actions receiving feedback. Another condition is the design of interactive multimedia educational resources by lecturers of engineering courses with students' engagement. The third condition is the possibility to support different learning styles. We carried out experimental work on the example of initial work with a theodolite in the course of engineering geodesy. Results showed that the application of interactive multimedia educational resources designed with these conditions led to a more successful execution of tasks with a shorter time for performing operations. We concerned the difference in grades of educational resources interactivity based on user- centered taxonomies. Results of experimental work showed that educational resources with a higher interactivity, allowing to perform creative tasks, led to a faster acquisition of engineering skills by students and, as a result, to the optimization of interactive operations
\end{abstract}

\section{Introduction}

For sustainable urban development, it is necessary to monitor the geometric parameters of buildings, structures and infrastructure. Only specialists trained in the field of geodetic measurements can carry out such monitoring at a high level of quality. Rapidly changing instruments and technologies for geodetic measurements require special treatment for the training of future specialists in universities. In vocational educational in urban development courses, as well as in engineering education in general, practical work with special

\footnotetext{
*Corresponding author: vlasov@bigpi.biysk.ru
} 
equipment remains an important component. It is not enough just to demonstrate the rules and algorithms of operations, modes, and settings of equipment. As a rule, learners need a long practice outside educational audiences with the solution of various problems similar to real professional situations for effective training. The use of interactive multimedia educational resources demonstrating the work of engineering equipment can create the prerequisites for the more successful training of university students for further practice at the initial stages of education.

In this article, we investigate a problem under what theoretically reasonable conditions of application of interactive multimedia educational resources the efficiency of students' training on work with the engineer equipment will be higher. Efficiency, in our opinion, should be demonstrated by more qualitative and successful performance of practical learning tasks with the equipment. We also intend to find out the differences in a gradation of interactivity degrees of multimedia educational resources limited to those, which can be developed in university courses by lecturers and students.

\section{Materials}

The importance of students' practical work with equipment in engineering education is beyond doubt. The relevant knowledge and skills are fixed in professional competences as educational outcomes of university courses. Students need to understand in which industrial operations it is expedient to use this or that equipment and to analyze and use the obtained data. In particular, for all future specialists in urban development, general requirements are knowledge of the basic geodetic equipment and ability to its adequate application in various professional situations. University course of geodesy covers work with a variety of devices: theodolite, levelling instrument, etc. Other engineering disciplines also strongly require an understanding of the principles of working with equipment.

The examples of the equipment used in the educational process of Novosibirsk State University of Architecture and Civil Engineering (SIBSTRIN) are given in Table 1.

Table 1. Equipment used in the initial stages of students' training in engineering courses.

\begin{tabular}{|l|l|}
\hline \multicolumn{1}{|c|}{ Equipment } & \multicolumn{1}{c|}{ Measured characteristics } \\
\hline Dial test indicator & Sags and displacements of different beams \\
\hline $\begin{array}{l}\text { Tensiometer, oscillography, signal } \\
\text { recorder }\end{array}$ & $\begin{array}{l}\text { Deformations and tension in structural } \\
\text { constructions }\end{array}$ \\
\hline $\begin{array}{l}\text { Multimeter, sine wave generator, } \\
\text { oscillography }\end{array}$ & $\begin{array}{l}\text { Frequency-response characteristics and } \\
\text { coefficient of the transistor amplifier }\end{array}$ \\
\hline $\begin{array}{l}\text { The lever-type Brinell machine, } \\
\text { Rockwell hardness-testing machine }\end{array}$ & Brinell hardness, Rockwell hardness \\
\hline $\begin{array}{l}\text { Electric stopwatch, special measuring } \\
\text { equipment }\end{array}$ & Inertia moment of the structural construction \\
\hline $\begin{array}{l}\text { Optical pyrometer, multimeter, } \\
\text { transformer }\end{array}$ & Radiation of heat of constructional materials \\
\hline Special device including manometer & Volume of granular material and porous solids \\
\hline Luxmeter & Light transmission factor for window units \\
\hline $\begin{array}{l}\text { Theodolite, alignment clamp, } \\
\text { electronic tacheometer }\end{array}$ & Horizontal angles and elevation angles \\
\hline Leveling instrument & Reduction of levels \\
\hline $\begin{array}{l}\text { Light rangefinder, laser rangefinder, } \\
\text { electronic tacheometer }\end{array}$ & Distances between points \\
\hline
\end{tabular}


Students study the professional operations performed by means of the special and general technical equipment. At the initial stages of working with devices, students quite often put out of commission the device or its parts that have a high cost. In this case, it is impossible to conduct a correct industrial operation; it will become erroneous. Therefore, the efficiency of practical training of students decreases in general.

Table 1 shows examples of only basic equipment used for the initial training of students in architectural and civil engineering. Contemporary engineering devices become more complex, they provide many functions. Special software, which is necessary for the processing of engineering data in digital formats, is becoming popular in urban development. Currently, almost every specialist in urban development measurement must have the knowledge and skills to perform and process operational and specific mode information, use general and professional software, analyze and prepare reports in digital forms.

Updating of equipment and software forces for continuous self-training not only specialists but also university lecturers. Lecturers should timely supplement and reorganize the learning contents of practical works, demonstrate to students new various educational situations at the available level and with the safety of equipment. Therefore, the observance of a high level of practical orientation in engineering education is a methodical problem in the conditions of rapid development of devices in the construction industry.

The use of educational environments, training computer programs, electronic educational resources with modeling of equipment operation, digital data of reports and imitation of industrial operations allows proposing the solution of the specified pedagogical problem. In engineering education, the number of examples of using e-learning tools for modeling professional situations is quite large. In cases of acquiring the students' initial experience with complex instruments and devices in practical work, multimedia tools are used most often. They include, for example, computer 3D simulations [1], animations [2], podcasts [3], etc.

It is important to note that, nevertheless, final diagnostics of the efficiency of practical skills is carried out not virtually, but in real-life tasks, for instance, at the mental construction of algorithm for working with equipment and performing engineering calculations.

In the process of achieving an understanding of the simulated labor actions meaning, the set of ways and methods of interaction with the computer program for students should increase and become more complicated gradually. Actually, the possibility of increasing the ways of interaction, acquisition of a semantic orientation should distinguish electronic educational resources from professional software. In the latter case, developers take into account the maximum coverage of professional needs defining the interface and capabilities of a computer system that, as a rule, do not correspond to the learning tasks at the initial stages.

A distinctive feature of the discussed multimedia tools is their purposeful development in accordance with educational objectives. Often individual lecturers or teams with the participation of university staff are engaged in developing or adapting multimedia resources for the students. Due to the development of software tools for rapid application, attracting students to develop educational recourses is becoming more and more frequent case $[4,5]$. Participation of students can be part of the academic course or be optional, with the invitation of more experienced, creative or active students. The invitation of students to creative cooperation with the lecturer and other students leads to the personal development of learners [6]. In addition, besides potential benefits for student-developers, the lecturer receives a variety of educational resources that are appropriate to the learning content. They are most focused on needs of the students using such resources. It is desirable that the 
students-developers belong to a contingent of potential users. Otherwise, the mismatch of representations can destroy the advantages of the semantic and conceptual proximity of users and developers.

As noted in numerous papers, interactivity property of electronic educational resources under certain conditions promotes active learning and engaging students in the educational process $[1,7,8]$. In case of modeling of industrial operations and modes of equipment, the interactivity of multimedia educational resources provides a great opportunity for students to provide an immersive experience in professional situations. Really, practical experience is always based on activity. The interactivity of electronic resources assumes potential activity of the student in the form of actions. The possible volume and nature of the student's actions, the degree of control over the educational environment determine the degree of educational tools' interactivity by various bases of classification [8].

Many authors in the studies of e-learning resources' interactivity use user-centric taxonomies. Depending on the capabilities provided to the user, all degrees of interactivity (if it presents) can be roughly divided into three hierarchical grades: low (Observe category), middle (Choose category) and high (Perform category) [8]. The difference of the first grady from the second one consists in lack of a possibility of choosing the order and volume of maintenance of educational content. The third grade is characterized by the ability of students to actively perform creative tasks. The third grade may be limited in application due to the high laboriousness in developing such resources by the lecturer and students. However, division into grades is rather conditional and can change depending on the taxonomy of levels of the interactivity used in this or that pedagogical research. It is important to note that the high degree of interactivity of the e-learning tool does not always mean a high degree of understanding of the educational content [9]. Therefore, conditions of the software design of interactive resources are significant enough.

In our opinion, it is the INTERACT model (the Integrated Model of Multimedia Interactivity) [9] most useful for understanding the property of interactivity which construction takes into account the personal characteristics and behavior of students. The model includes not only the traditionally considered capabilities of the Learning Environment, but also the Behavioral Activity component, the Cognitive and Metacognitive Activities component, the Emotions/Motivation component, and formed by the student, ultimately, the Mental Model. Most of the components are interconnected in pairs with each other. In addition, the context for the structure of the INTERACT model depends on the Learner Variables, including previous students' experience, their ability to self-organize, and other individual characteristics.

In our case, for the simulation of working with professional equipment or modeling professional situations, the user's actions are of key importance. Really, at all other identical components of the Integrated Model of Multimedia Interactivity, the degree of interactivity will depend on the properties of the educational resource taking into account the potential interaction with students-users. It is characterized by the interconnection of the Learning Environment and the Behavioral Activity components. An obvious condition is closer compliance with educational actions, correct or wrong, during the further real work of students with devices. The educational nature of multimedia resources also presupposes the presence of assessment functions in the learning environment and, perhaps, monitoring and correction of methods or algorithms of students' activities. Forecasting the activity of students-users during the work with interactive multimedia educational resources can be effectively decided by involving students in the development what we already mentioned.

The property of interactivity of multimedia educational resources will not be realized without the software design of other components of the considered model. The content of the Emotions/Motivation component can also be provided by the communicative support of the students-developers by the youth students' community. Teams of students-developers in 
cooperation with the lecturer conduct a questionnaire, receive feedback from other students. Thus, the entire students' community can potentially influence structure, content, and characteristics of the developed educational resources.

At last, the Cognitive and Metacognitive Activities component stimulates students to the achievement of the best educational outcomes if suitable learning styles of training are used $[10,11]$. Learning styles have a direct impact on the behavior of students, i.e. user actions [10]. In the development of multimedia resources, the accounting of learning styles includes, among other things, representation of content using an obligatory combination of text, video, aural and interaction [11]. Such requirement guarantees engagement of all students due to perception as one of the dimensions in the classification of learning styles.

Thus, we assumed that the proposed conditions for the software design of the components of student's interaction with the interactive multimedia educational resource can lead to the formation of a mental model of professional processes and operations with the use of special equipment. Due to the commonality of mental and external activities, effective training has to be shown by the more successful performance of practical educational tasks with the equipment at the initial stages.

The second assumption concerns the degree of interactivity of multimedia educational tools. In the context of our study, we assumed that with the software engineering of multimedia educational resources with a higher gradation of interactivity imitating work with geodetic equipment lead to a faster development of engineering devices..

\section{Methods and Results}

Experimental work was carried out at the Novosibirsk State University of Architecture and Civil Engineering (SIBSTRIN), which is a major center for training specialists in architectural and civil engineering including specialists in urban development. One of the most important general university courses is engineering geodesy. In the course of engineering geodesy, students learn to work on various geodetic devices. The curriculum of engineering geodesy includes lectures, seminars, and laboratory lessons. Educational geodetic practice is an obligatory component of training; it is conducted after the end of the course. During auditory lessons, students get acquainted with devices, the order of operation and methods of applying geodetic instruments in different industrial operations including urban development. Further, students apply the acquired knowledge in professional situations during the practice.

For verification of our assumptions, we chose a material for the theodolite study. Theodolites and electronic tacheometers are among the most sophisticated devices for students in the initial acquaintance. When studying the theodolite, the great number of shortcomings and errors occurs that leads to additional gaps in the study of the electronic tacheometer, which is an instrument of the same operating principle as a theodolite. Experimental work is organized on the educational material of the laboratory lesson "Theodolitic works". According to the plan of the lesson, each student should use the theodolite to measure one horizontal angle using "sights" method, perform measurement control, record the results in a workbook and present it to the lecturer. Before the measurement, it is necessary to bring the theodolite to the working position, and then perform the guidance on the objects to be sighted, make counts, calculate angles in, and conduct the control. With an allowable divergence of the angles in the sights, the control is deemed to be performed, and the angle is considered to be measured correctly. The assessment criteria are the number of shortcomings, and time of performance of a task with the device. Typically, a specialist measures the horizontal angle with a theodolite in a time of two to five minutes. At the initial stages of the work, students spend up to 80 minutes performing the task, sometimes with the help of a lecturer. 
Among the interactive multimedia educational resources developed by the lecturer together with students in previous years, it was selected ones, which model work with the theodolite. They included an animated film on working with the theodolite (low interactivity), an electronic lecture summary with feedback, including calculations of the obtained data (middle interactivity), "Electronic textbook: geodetic devices" with a 3D animated explanation, the website of a geodetic discipline lecturer with creative tasks (high interactivity). The website of the lecturer contains samples of students' solutions to creative professional tasks. All listed educational resources include ways to provide information for persons with a predominance of visual, audial and kinesthetic perception.

For carrying out experimental work from the general selection of second-year students in 300 people three groups were selected. For receiving reliable data of group were chosen by the principle of similar average progress.

To conduct experimental work from the general selection of second-year students in 300 people, three groups were selected. To obtain reliable data, the groups were selected according to the principle of similar academic grade average.

All three groups received theoretical material and the description of the future task for one week prior to laboratory work. In addition, all students were provided with methodical instructions in printed and electronic text forms; available textbooks are recommended. Students were offered to be prepared for the performance of a practical task on measurement with a theodolite. Students were asked to prepare for the practical task of measuring with a theodolite. Group 1 did not receive additional interactive educational resources. Group 2 is provided with animation on working with the theodolite (Figure 1) and "Electronic lecture summary", which have low and medium interactivity.

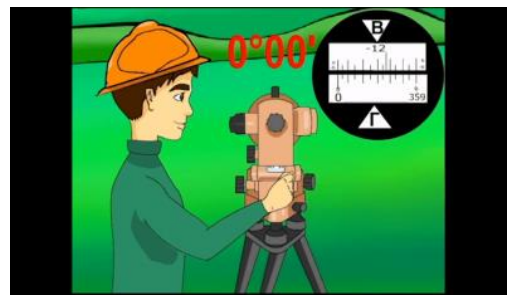

Fig. 1. Fragment of educational animation on the work with a theodolite developed by students.

Group 3 is provided with electronic educational resources of high and medium interactivity: "Electronic textbook: geodetic instruments" (Figure 2) and free access to the site of the geodesic discipline lecturer.

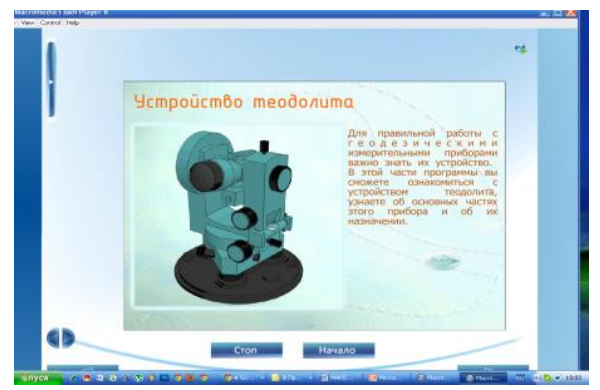

Fig. 2. Fragment of multimedia educational resource "Electronic textbook: geodetic devices" developed by students.

The purpose of the experimental work was to compare assessing data of the practical task with an engineering device, including the number of reported shortcomings (accuracy), time and independence of students' performance, in different conditions. When carrying out 
experiment three students' groups were offered identical tasks within laboratory lessons "Theodolitic works". Laboratory works were performed in the geodetic laboratory of Sibstrin. The serviceable theodolite fixed on a metal column with the concrete basis was provided to each student for measurement. In addition, in the laboratory, there were computers with pre-installed electronic educational resources on engineering geodesy.

Members of the Engineering Geodesy Chair and laboratory assistant conducted experimental laboratory lessons. Before beginning, laboratory assistant measured all the horizontal angles offered to the students. Further, the table of values of angles was with the lecturer; therefore, students could not falsify the result of measurements. When performing laboratory work the main shortcomings at measurements were revealed. These shortcomings included the following: incorrect preparation of the theodolite for work, mistakes in the order of the measurements, errors in calculations, errors in the correctness of recording the results in the log, incorrect capture of counting.

During the experiment, the laboratory assistant recorded the time of performance of each student's work. The self-executing measurement process was maximum 75 minutes. Students who did not cope with the task carried out the measurement in additional 5-10 minutes together with the lecturer.

Accuracy and self-execution of the practical task for three groups are presented in Table 2. In the third group, more than half of the students completed the task without any shortcoming. In other groups, most students have no more than one shortcoming. Several students in first and second groups have two or three shortcomings. However, the application of Mann-Whitney U-test was not revealed in pairs in groups of significant differences in the distribution of counts of students' shortcomings. Therefore, it can be concluded that all the educational tools for all groups contained learning the content of proper quality; i.e. there was no difference in the geodesy content for all types of educational resources.

Table 2. Accuracy and self-execution of the practical task.

\begin{tabular}{|c|c|c|c|c|c|}
\hline Group & $\mathrm{N}$ & $\begin{array}{c}\text { Self-execution } \\
\text { of task }\end{array}$ & $\begin{array}{c}\text { Percentage of } \\
\text { tasks' self- } \\
\text { executing, \% }\end{array}$ & $\begin{array}{c}\text { Shortcomings, } \\
\text { mean }\end{array}$ & $\begin{array}{c}\text { Shortcomings, } \\
\text { standard } \\
\text { deviation }\end{array}$ \\
\hline Group 1 & 19 & 16 & 84 & 1.11 & 0.05 \\
\hline Group 2 & 20 & 19 & 95 & 0.7 & 0.86 \\
\hline Group 3 & 21 & 21 & 100 & 0.33 & 0.48 \\
\hline
\end{tabular}

The need for assistance from the lecturer to several students, reflected in the percentage of students with self-executing of the task, characterizes the general trend but does not contain statistically reliable information on the sense of the experiment. More informative are data on time students performed measurements using the theodolite (Table 3).

Table 3. Characteristics of students' time of measurement using theodolites (in minutes).

\begin{tabular}{|c|c|c|c|c|c|}
\hline Group & Minimum time & $\begin{array}{c}\text { Maximum } \\
\text { time }\end{array}$ & $\begin{array}{c}\text { Maximum time of } \\
\text { tasks' self-executing }\end{array}$ & $\begin{array}{c}\text { Time, } \\
\text { mean }\end{array}$ & $\begin{array}{c}\text { Time, } \\
\text { standard } \\
\text { deviation }\end{array}$ \\
\hline Group 1 & 19 & 80 & 70 & 47.88 & 16.22 \\
\hline Group 2 & 16 & 80 & 58 & 27.53 & 13.69 \\
\hline Group 3 & 10 & 33 & 33 & 18.95 & 6.91 \\
\hline
\end{tabular}

In the first group, the mean time is $47.88(\mathrm{SD}=16.22)$. In the second group, the mean score is $27.53(\mathrm{SD}=13.69)$. The results of the U-test show a significant difference between these groups $(\mathrm{U}=69, \mathrm{p}<0.01)$ indicating that students using interactive multimedia resources 
with at least low or middle grade of interactivity had significantly lower time than students with no using interactive multimedia resources at all.

Thus, the use of interactive multimedia educational resources in accordance with the considered model and conditions of software design really show more successful students' performance of practical educational tasks with the equipment at initial stages.

In the third group, the mean score is $18.95(\mathrm{SD}=6.91)$. Statistical analysis of results in the second group and the third group with the U-test show a significant difference between these groups $(\mathrm{U}=118, \mathrm{p}<0.01)$ indicating that students using interactive multimedia resources with high and middle grades of interactivity had significantly lower time than students learners students using interactive multimedia resources with low and middle grade of interactivity.

Since the third group used multimedia educational resources of greater interactivity than for the second group, the second assumption is also confirmed. Consequently, educational resources simulating work with geodetic equipment with a higher gradation of interactivity in the interpretation of the considered model can lead to a faster acquisition of engineering skills on work with professional devices.

\section{Conclusions}

In this paper, a study was presented investigating issues of the effectiveness of the use of interactive multimedia educational resources in in urban development courses on the example of working with geodetic instruments. The theoretical basis for the study was the conditions for the design of the components of the learner interaction system with an interactive multimedia educational resource in accordance with the Integrated Model of Multimedia Interactivity [9].

We carried to next conditions:

participation of lecturers of university courses together with students-developers in the development of interactive multimedia educational resources based on interaction with students-users;

multimedia modelling of industrial operations and the modes of the professional equipment with feedback and the ability to perform correct and erroneous learning actions;

possibility of supporting different learning styles in interactive multimedia educational resources.

We confirmed experimentally that under supposed conditions increase in a gradation of interactivity degree of multimedia educational resources based on user-centered taxonomies can exert a positive impact on the efficiency of initial training when working with equipment. The high grade of interactivity is associated with the possibility of students implementing a creative approach to solving professional problems with the use of multimedia educational resources. Clarifying the characteristics of the interactivity degrees of multimedia educational resources for training of students on work with engineering equipment in accordance with low, medium or high interactivity can serve a subject for further researches.

Results of experimental work showed that software engineering and application of interactive educational resources for university student training in urban development courses led to students' understanding of professional processes and operations with equipment using the example of engineering geodesy before the beginning of practical work. The external manifestation of personal understanding at the mental level consists in the faster initial performance of practical learning tasks with difficult engineer equipment. The achieved understanding will allow specialists to master the more sophisticated modern instruments and optimize industrial operations. 


\section{References}

1. M. G. Violante, E. Vezzetti, Comput Appl Eng Educ, 23(1), 72-91 (2015)

2. T. C. Despotakis, G. E. Palaigeorgiou, I. A. Tsoukalas, ET\&S, 10 (1), 196-205 (2007)

3. A. Gorra, J. Finlay, E JEL, 7 (3), 257-264 (2009)

4. B. Loch, J. Lamborn, IJEMST, 47 (1), 29-44 (2016)

5. N. E. Sanders, C. Faesi, A. A. Goodman, J Sci Educ Technol, 23, 431-440 (2014)

6. O. Solnyshkova, I. Makarikhina, EMMFT 2017 - Energy Management of Municipal Transportation Facilities and Transport, 90, 012022 (IOP Conference Series: Earth and Environmental Science, 2017)

7. G. E. Kennedy, JILR, 15, 43-61 (2004)

8. J. Helfrich, S. Moulton, E-Learn 2009 - World Conference on E-Learning in Corporate, Government, Healthcare, and Higher Education, 2668-2674 (AACE, 2009)

9. S. Domagk, R. Schwartz, J. L. Plass, Comput Human Behav, 26 (5), 1024-1033 (2010)

10. Kinshuk, T.-C. Liu, S. Graf, ETR\&D, 57 (6), $739-752$ (2009)

11. M. Sankey, D. Birch, M. Gardiner, IJEDICT, 7 (3), 18-35 (2012) 